\title{
New Bifunctional Metal-Organic Frameworks and Their Utilization in One-Pot Tandem Catalytic Reactions
}

\author{
Published as part of the Crystal Growth and Design Israel Goldberg Memorial virtual special issue \\ Subhradeep Mistry, Anupam Sarkar, and Srinivasan Natarajan*(i) \\ Framework Solids Laboratory, Solid State and Structural Chemistry Unit, Indian Institute of Science, Bangalore 560012, India
}

Supporting Information

\begin{abstract}
Two new metal-organic framework (MOF) compounds were synthesized by a room temperature slow diffusion reaction. The compounds, $\left[\mathrm{Cd}_{3}\left(\mathrm{C}_{8} \mathrm{H}_{3} \mathrm{SO}_{7}\right)_{2}\right.$ $\left.\left(\mathrm{C}_{10} \mathrm{H}_{8} \mathrm{~N}_{4}\right)_{3}\left(\mathrm{C}_{3} \mathrm{H}_{7} \mathrm{NO}\right)_{2}\right]\left(\mathrm{C}_{3} \mathrm{H}_{7} \mathrm{NO}\right)_{2} \cdot\left(\mathrm{CH}_{3} \mathrm{OH}\right)_{4}, \quad \mathrm{I}$, and $\left[\mathrm{Cd}_{3}\left(\mathrm{C}_{8} \mathrm{H}_{3} \mathrm{SO}_{7}\right)_{2}\left(\mathrm{C}_{12} \mathrm{H}_{10} \mathrm{~N}_{4}\right)_{3}\left(\mathrm{C}_{3} \mathrm{H}_{7} \mathrm{NO}\right)_{2}\right]\left(\mathrm{C}_{12} \mathrm{H}_{10} \mathrm{~N}_{4}\right)$. $\left(\mathrm{C}_{3} \mathrm{H}_{7} \mathrm{NO}\right)_{2}$, II, have comparable structures formed by $\mathrm{Cd}$ sulfoisopthalate layers cross-linked by bipyridyl linkers forming three-dimensional structures. The compounds have both Lewis acidic (Cd metal centers) as well as basic (azine, free pyridine, and uncoordinated sulfo oxygens) sites, and they exhibited good catalytic activity for one-pot tandem deacetalization-Knoevenagel condensation reactions. The compounds exhibit catalytic activity both in the presence of a solvent as well as in solvent-free conditions. Compound I also exhibits good proton conductivity at room temperature.

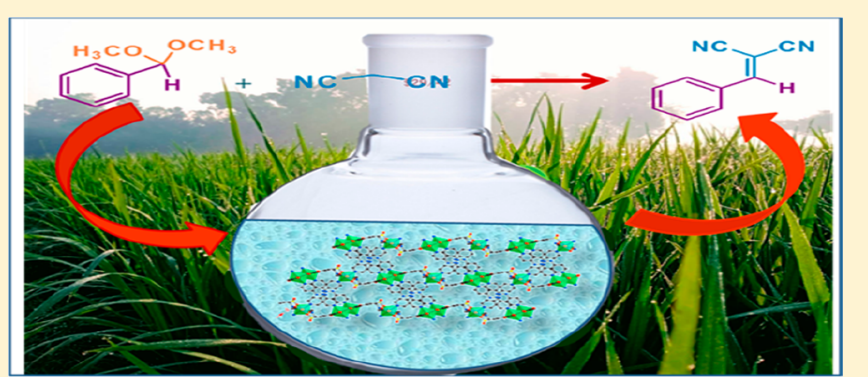

\section{INTRODUCTION}

Metal-organic frameworks (MOF) or coordination polymers (CP) have occupied a central stage during the last two decades. $^{1-4}$ The aesthetic structures, large functional pores, which are often flexible and tunable in nature, ${ }^{5-8}$ make this class of compounds attractive and have found applications in storage, ${ }^{9-12}$ separation, ${ }^{13-16}$ catalysis, $^{17-22}$ drug delivery, ${ }^{23-25}$ sensing, ${ }^{26,27}$ etc.

MOFs with their extra-large pore openings and channels could be candidates for exploring heterogeneous catalytic studies and can provide good activity as well as selectivity. ${ }^{28}$ Thus, there is considerable interest to investigate MOFs as a heterogeneous catalyst in many catalytic reactions. One of the important developments over the years in organic reactions/ transformations is to generate processes that are environmentally benign and with good atom economy. One such process is one-pot tandem reactions. In a tandem or cascade reaction, two or more reactions proceed successively within the same reaction pot, which reduces energy consumption, waste of chemicals, and the reaction time. ${ }^{29}$

One-pot reaction types include, but are not limited to, cascade (domino) process, ${ }^{30,31}$ tandem catalysis (catalysis performed sequentially), ${ }^{32}$ multifunctional catalysts having more than one active site, ${ }^{33}$ and reactions involving two distinct catalysts. ${ }^{34}$ The one-pot catalytic reactions present certain difficulties (i) controlling and optimizing selectivity and (ii) competing interactions (usually detrimental) between multiple catalytic sites and catalysts, which presents opportunities to explore newer catalysts. ${ }^{35}$ The attractive side of these one-pot reactions, on the other hand, is the possibility of isolating energetically unfavorable products. We have been interested in these one-pot tandem reactions as the MOFs provide a suitable platform to investigate multifunctional catalysts that would help in different types of transformations under similar reaction conditions.

In the present study, we have employed two organic ligands, sodium salt of 5-sulfoisopthalic acid ( $\left.\mathrm{Na}-\mathrm{C}_{8} \mathrm{H}_{3} \mathrm{SO}_{7}-\mathrm{NaSIPA}\right)$ and two pyridine based organic linkers 4,4'-azopyridine $\left(\mathrm{C}_{10} \mathrm{H}_{8} \mathrm{~N}_{4}\right.$ - $\left.\mathrm{ABPY}\right)$ and 1,4-bis(4-pyridyl)-2,3-diaza-1,3butadiene $\left(\mathrm{C}_{12} \mathrm{H}_{10} \mathrm{~N}_{4}-\mathrm{BPDB}\right)$ along with the cadmium salts to prepare two new three-dimensional (3D) MOFs $\left[\mathrm{Cd}_{3}\left(\mathrm{C}_{8} \mathrm{H}_{3} \mathrm{SO}_{7}\right)_{2}\left(\mathrm{C}_{10} \mathrm{H}_{8} \mathrm{~N}_{4}\right)_{3}\left(\mathrm{C}_{3} \mathrm{H}_{7} \mathrm{NO}\right)_{2}\right]\left(\mathrm{C}_{3} \mathrm{H}_{7} \mathrm{NO}\right)_{2}$. $\left(\mathrm{CH}_{3} \mathrm{OH}\right)_{4}$ (I) and $\left[\mathrm{Cd}_{3}\left(\mathrm{C}_{8} \mathrm{H}_{3} \mathrm{SO}_{7}\right)_{2}\left(\mathrm{C}_{12} \mathrm{H}_{10} \mathrm{~N}_{4}\right)_{3^{-}}\right.$ $\left.\left(\mathrm{C}_{3} \mathrm{H}_{7} \mathrm{NO}\right)_{2}\right]\left(\mathrm{C}_{12} \mathrm{H}_{10} \mathrm{~N}_{4}\right) \cdot\left(\mathrm{C}_{3} \mathrm{H}_{7} \mathrm{NO}\right)_{2}$ (II).

The hexa-coordinated $\mathrm{Cd}$ metal centers have been known to act as Lewis acidic centers and have been exploited for several applications that include heterogeneous catalysis. ${ }^{36,37}$ In addition, the presence of the sulfo group (uncoordinated sulfo oxygens with lone pairs) as well as azine and uncoordinated pyridine sites can potentially act as Lewis base centers. ${ }^{38-41}$ The possibility of combining the Lewis acidic and basic properties in single MOFs provides an attractive option for exploring catalytic reactions. One reaction that would combine the Lewis acidity and basicity would be the deacetalization-Knoevenagel (DK) reaction. There have been studies in the literature exploring such a tandem catalytic

Received: September 3, 2018

Revised: November 2, 2018

Published: December 18, 2018 
reaction. ${ }^{42-45}$ In the present study, the isolated compounds possess some of the desirable properties to carry out the tandem catalysis that would involve both the Lewis acidic as well as basic reaction centers. We have explored such a reaction as part of the present investigations and found the present compounds to be active as good heterogeneous catalysts. In addition, we have also discussed the proton conductivity behavior of compound I. In this paper, we present the synthesis, structure, tandem catalytic behavior, and proton conductivity studies on the two compounds, I and II.

\section{EXPERIMENTAL SECTION}

Synthesis of Compounds I and II. All the chemicals were obtained from commercially available sources. The ligand BPDB was synthesized following the established procedure. ${ }^{46}$ All the syntheses of the MOFs were carried out at room temperature employing slow diffusion of the reactants separated by immiscible layers. Typically, $0.04 \mathrm{mmol}$ of NaSIPA salt $(10.7 \mathrm{mg})$ and $0.04 \mathrm{mmol}$ of bipyridine linkers [ABPY for I $(7.4 \mathrm{mg})$ and BPDB for II $(8.4 \mathrm{mg})$ ] were dissolved in $2 \mathrm{~mL}$ of methanol and were transferred to a $5 \mathrm{~mL}$ culture tube (capped) and carefully layered over a $2 \mathrm{~mL}$ of dimethylformamide (DMF) solution containing $0.04 \mathrm{mmol}$ of $\mathrm{Cd}\left(\mathrm{NO}_{3}\right)_{2} \cdot 4 \mathrm{H}_{2} \mathrm{O}$ (12.3 mg). After 2-3 days, reddish orange (I) and yellow (II) colored crystals started to form on the wall of the tubes. The reaction was allowed to continue for 1 week, and then the crystals were separated from the mother liquor and washed with a 1:1 mixture of DMF and methanol solution under vacuum filtration and dried at ambient conditions. Yields: $89 \%$ (I) and $82 \%$ (II); based on the metal salts (Table S1).

Initial Characterization. All the compounds were characterized by elemental analysis (C, H, N, S; Thermo Finnigan EA Flash 1112), powder X-ray diffraction (PXRD; PANalytical, Empyrean), IR (Perking-Elmer Spectrum 1000), thermogravimetric analysis (TGA; Mettler-Toledo), and UV/vis absorption studies (Perking-Elmer, Lambda-35). Elemental analysis results are presented in Table S2. The PXRD patterns of the samples were recorded at room temperature $\left(\mathrm{CuK}_{\alpha}\right)$, and the observed PXRD patterns were consistent with the simulated PXRD patterns generated from the structures determined by the single-crystal XRD studies (Supporting Information, Figure S1).

Room temperature IR spectroscopic studies were carried out in the mid-IR region using $\mathrm{KBr}$ pellets, which exhibited characteristic bands (Figure S2). A sharp band at $\sim 1735 \mathrm{~cm}^{-1}$ could be assigned to the presence of the -COO group of the SIPA ligand in compounds I and II. The bands at $1230 \mathrm{~cm}^{-1}$ (I) and $1160 \mathrm{~cm}^{-1}$ (II) could be due to the asymmetric and symmetric stretching band of the $S=0$ group of the ligand. The strong sharp band at $\sim 1040 \mathrm{~cm}^{-1}$ could be due to the $\mathrm{S}-\mathrm{O}$ stretching. ${ }^{47}$ The strong band near $\sim 1610 \mathrm{~cm}^{-1}$ in II could be assigned to the presence of the azine group $(-\mathrm{C}=\mathrm{N}-)$ of the BPDB ligand. ${ }^{48,49}$ A sharp band at $\sim 1646 \mathrm{~cm}^{-1}$ (I) and $1640 \mathrm{~cm}^{-1}$ (II) is for the $\mathrm{C}=\mathrm{O}$ stretch of $\mathrm{DMF}^{50}$ and a band at around $3540^{-1}$ (I) could be for the $\mathrm{OH}$ stretch of $\mathrm{MeOH}$.

UV-vis spectra of compounds I and II recorded at room temperature exhibit broad absorption bands in the visible region (Figure S3). For I, two maxima centered at $\sim 350 \mathrm{~nm}$ and $\sim 480 \mathrm{~nm}$ were observed, and for II one maximum at $\sim 380 \mathrm{~nm}$ with a shoulder at $\sim 330 \mathrm{~nm}$ was noted. The absorption bands arise due to the intraligand charge transfer $\left(\mathrm{n} \rightarrow \pi^{*}\right.$ or $\left.\pi \rightarrow \pi^{*}\right)$. The observed UVvis spectra for I and II are similar to those observed before. ${ }^{51}$

The solid-state photoluminescence (PL) studies of compounds I and II were carried out at room temperature on the powdered sample (Figure S4). The compounds I and II were excited using a wavelength of 350 and $380 \mathrm{~nm}$, respectively. An emission band at $\sim 395 \mathrm{~nm}$ with two shoulders at ca. 490 and $530 \mathrm{~nm}$ was observed for compound I (Figure S4a). For II, a maximum at $\sim 450 \mathrm{~nm}$ with two shoulders at $\sim 485$ and $525 \mathrm{~nm}$ was observed (Figure S4b). The observed emissions are due to intraligand emissions. Similar observations have been made before. ${ }^{51,52}$
Single-Crystal Structure Determination. Suitable single crystals of compounds I and II were selected and mounted with a fiber loop. The single-crystal data were collected at $100(2) \mathrm{K}$ on an Oxford Xcalibur (Nova) diffractometer equipped with an EOS CCD detector. The X-ray was generated by operating at $50 \mathrm{kV}$ and $0.8 \mathrm{~mA}$ by using $\operatorname{MoK} \alpha(\lambda=0.71073 \mathrm{a})$ radiation. The refinement of the cell and the data reduction were carried out using CrysAlis RED. ${ }^{53}$ The structures were solved using direct method, and refinement was accomplished by employing SHELX-2014 present in WINGx suite of programs (version 1.63.04a). ${ }^{54}$ The hydrogens could be assigned from the difference Fourier map, and for the final refinement the hydrogens were fixed at the geometrically ideal position and refined using the riding mode. The full-matrix least-squares refinement against $\left|F^{2}\right|$ was executed on the WinGx package of programs. ${ }^{55}$ The final refinements were carried out including atomic positions of all the atoms, anisotropic thermal parameters for all the non-hydrogen atoms, and isotropic thermal parameters for all the hydrogen atoms. All the details of structural parameters and refinement details are listed in Table 1. Important bond lengths and bond angles are presented in

Table 1. Crystal Data and Structure Refinement Parameters for All the Compounds ${ }^{a}$

\begin{tabular}{|c|c|c|}
\hline structural parameter & I & II \\
\hline $\begin{array}{l}\text { empirical formula } \\
\text { crystal system }\end{array}$ & $\begin{array}{l}\mathrm{C}_{62} \mathrm{H}_{58} \mathrm{~N}_{16} \mathrm{O}_{22} \mathrm{~S}_{2} \mathrm{Cd}_{3} \\
\text { triclinic }\end{array}$ & $\begin{array}{l}\mathrm{C}_{76} \mathrm{H}_{74} \mathrm{~N}_{20} \mathrm{O}_{18} \mathrm{~S}_{2} \mathrm{Cd}_{3} \\
\text { triclinic }\end{array}$ \\
\hline space group & $P \overline{1}($ No. 2$)$ & $P \overline{1}($ No. 2$)$ \\
\hline$a(\AA)$ & $10.1392(5)$ & $10.2282(14)$ \\
\hline$b(\AA)$ & $13.6080(6)$ & $13.5641(19)$ \\
\hline$c(\AA)$ & $13.6470(6)$ & $15.9140(2)$ \\
\hline$\alpha(\mathrm{deg})$ & $73.330(10)$ & $108.464(3)$ \\
\hline$\beta(\operatorname{deg})$ & $82.470(10)$ & $98.421(4)$ \\
\hline$\gamma(\mathrm{deg})$ & $81.922(10)$ & $97.469(4)$ \\
\hline$V\left(\AA^{3}\right)$ & $1777.71(14)$ & $2034.70(5)$ \\
\hline $\mathrm{Z}$ & 1 & 1 \\
\hline$T / \mathrm{K}$ & $100(2)$ & $100(2)$ \\
\hline$\rho\left(\right.$ calc $\left./ \mathrm{g} \mathrm{cm}^{-3}\right)$ & 1.663 & 1.597 \\
\hline$\mu\left(\mathrm{mm}^{-1}\right)$ & 1.034 & 0.909 \\
\hline$\lambda(\mathrm{Mo} \mathrm{K} \alpha / \AA)$ & 0.71073 & 0.71073 \\
\hline$\theta$ range $(\mathrm{deg})$ & 3.095 to 25.998 & 3.042 to 26.000 \\
\hline$R_{\text {int }}$ & 0.0509 & 0.0333 \\
\hline $\begin{array}{l}R \text { indexes } \\
\quad[I>2 \sigma(I)]\end{array}$ & $\begin{array}{l}R_{1}=0.0483 \\
w R_{2}=0.1306\end{array}$ & $\begin{array}{l}R_{1}=0.0617 \\
\quad w R_{2}=0.1714\end{array}$ \\
\hline$R$ indexes (all data) & $\begin{array}{l}R_{1}=0.0498 \\
w R_{2}=0.1317\end{array}$ & $\begin{array}{l}R_{1}=0.0665 \\
w R_{2}=0.1746\end{array}$ \\
\hline \multicolumn{3}{|c|}{$\begin{array}{l}{ }^{a} R_{1}=\sum\left|F_{\mathrm{o}}\right|-\left|F_{\mathrm{c}} \| / \sum\right| F_{\mathrm{o}} \mid ; w R_{2}=\left\{\sum\left[w\left(F_{\mathrm{o}}{ }^{2}-F_{\mathrm{c}}{ }^{2}\right)\right] / \sum\left[w\left(F_{\mathrm{o}}{ }^{2}\right)\right.\right. \\
\left.\left.{ }^{2}\right]\right\}^{1 / 2} \cdot w=1 /\left[\rho^{2}\left(F_{\mathrm{o}}\right)^{2}+(a P)^{2}+b P\right] . P=\left[\max \left(F_{\mathrm{o}}, \mathrm{O}\right)+2\left(F_{\mathrm{c}}\right)^{-2}\right] / 3 \\
\text { where } a=0.0699 \text { and } b=11.4708 \text { for } \mathbf{I} \text { and } a=0.0959 \text { and } b= \\
12.9591 \text { for II. }\end{array}$} \\
\hline
\end{tabular}

Tables S3 and S4. The supplementary crystallographic data for this paper can be found in CCDC 1838396-1838397. The Cambridge Crystallographic Data Centre (CCDC) provides free access to the single crystal data.

Catalytic Studies. To perform the tandem catalytic reactions, an optimization of the catalytic conditions was investigated. Thus the deacetalization and Knoevenagel condensation reactions were carried out independently with the MOFs as catalyst in different solvents such as $\mathrm{EtOH}, \mathrm{MeOH}$, toluene, MeCN, DMA, and DMF. The investigations reveal that catalytic performance was optimal when DMF was employed as the solvent. Thus we have chosen DMF as the solvent for the tandem one-pot DK reactions. The next step is to perform the catalytic reactions at different temperatures. We observed that the deacetalization was slow at lower temperatures. Our studies indicate that optimum products were observed when the reactions were carried out at $353 \mathrm{~K}$. 


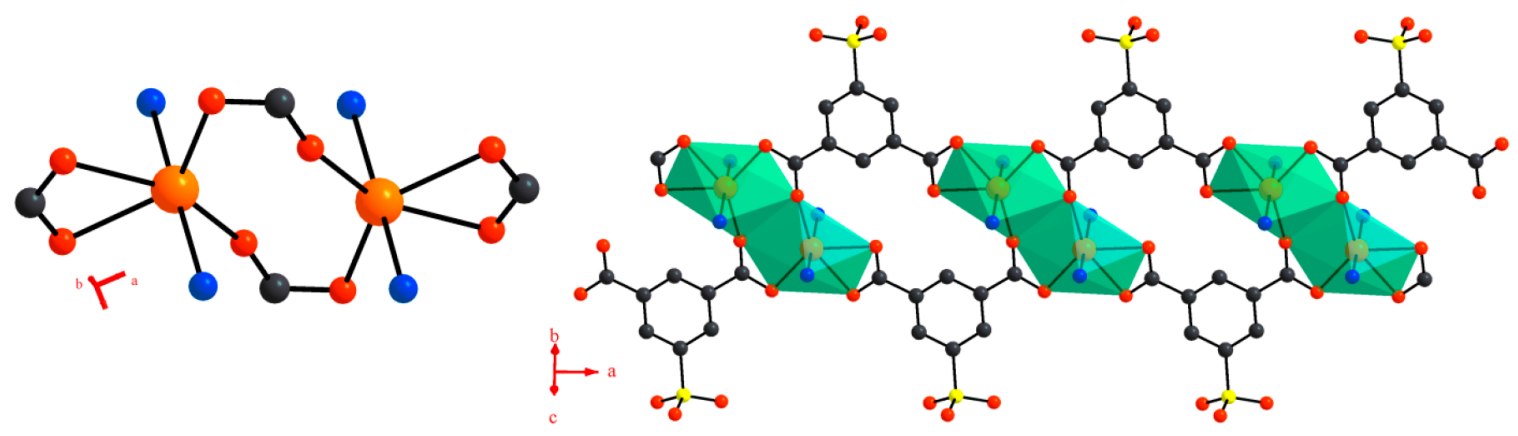

(a)

(b)
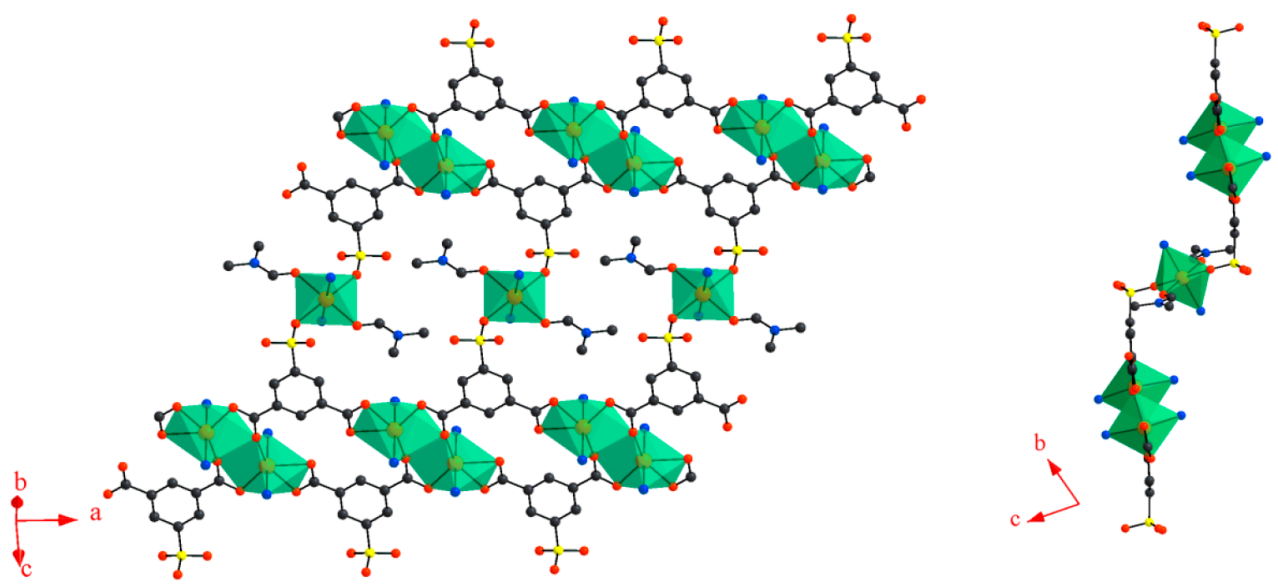

(c)

(d)

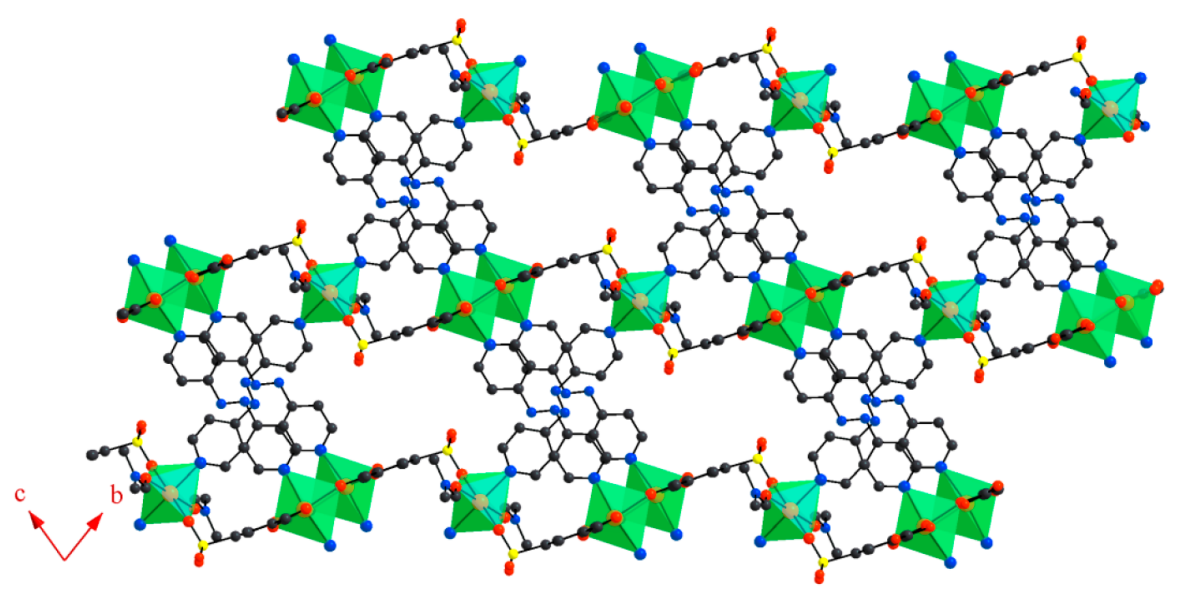

(e)

Figure 1. (a) View of $\left[\mathrm{Cd}_{2}\left(\mathrm{CO}_{2}\right)_{4}\right]$ unit in $\mathbf{I}\left(\mu_{1}-\eta^{1}: \eta^{1}\right.$ and $\mu_{2}-\eta^{1}: \eta^{1}$ bridgings can be observed); (b) view of 1D double chain formed by SIPA and $\mathrm{Cd}$ metal; (c) view of $2 \mathrm{D}$ layer of Cd and SIPA ligand in the $a b c$ plane; (d) view of 2D layer from the $a$ axis; (e) view of the 3D structure of I (lattice solvents and hydrogens are omitted for clarity; Cd atoms are shown in green colored polyhedral).

To optimize the amount of the catalysts that may be required, we have taken the catalyst (compound $\mathbf{I}$ ) in three different amounts $[5$ $\mathrm{mg}(0.28 \mathrm{~mol} \%), 10 \mathrm{mg}(0.56 \mathrm{~mol} \%)$, and $25 \mathrm{mg}(1.4 \mathrm{~mol} \%)]$ to carry out the tandem DK reactions. The yields were better when the catalytic studies were carried out using $10 \mathrm{mg}$ of the sample. Higher quantity of the catalyst did not result in improved yields for the product.

The independent deacetalization and Knoevenagel condensation reactions were carried out by taking $1 \mathrm{mmol}$ of the reactants and 10 $\mathrm{mg}$ of catalysts in $2 \mathrm{~mL}$ of DMF. For the tandem one-pot DK reaction also we have taken similar quantities of the reactant: benzaldehyde dimethyl acetal (BA) $(1 \mathrm{mmol})$ and malononitrile (MN) $(1 \mathrm{mmol})$ along with the catalyst $(10 \mathrm{mg} ; 0.56 \mathrm{~mol} \%)$ in $2 \mathrm{~mL}$ of DMF as the solvent in a round-bottom (RB) flask under nitrogen atmosphere. The catalysts were activated at $373 \mathrm{~K}$ overnight before being employed for the catalytic studies. The mixture was first stirred for $3 \mathrm{~min}$ at room temperature, and the catalytic reaction was carried out at $353 \mathrm{~K}$. The progress of the reaction was monitored by thin-layer chromatography (TLC) at a regular interval of time. After $5 \mathrm{~h}$ of reaction, the mixture was filtered and washed with $1 \mathrm{~mL}$ of DMF along with $\mathrm{CH}_{2} \mathrm{Cl}_{2}$. The organic product was extracted with $\mathrm{CH}_{2} \mathrm{Cl}_{2}$ and water. At the end, the 
crude product was purified using silica gel column chromatography (hexane/ethyl acetate) and characterized by ${ }^{1} \mathrm{H}$ NMR spectroscopy.

\section{RESULTS AND DISCUSSION}

Structure of $\left[\mathrm{Cd}_{3}\left(\mathrm{C}_{8} \mathrm{H}_{3} \mathrm{SO}_{7}\right)_{2}\left(\mathrm{C}_{10} \mathrm{H}_{8} \mathrm{~N}_{4}\right)_{3}\left(\mathrm{C}_{3} \mathrm{H}_{7} \mathrm{NO}\right)_{2}\right]-$ $\left.\mathrm{C}_{3} \mathrm{H}_{7} \mathrm{NO}\right)_{2} \cdot\left(\mathrm{CH}_{3} \mathrm{OH}\right)_{4}$ (I). Compound I crystallizes in the triclinic $(P \overline{1})$ space group and has 53 non-hydrogen atoms present in the asymmetric unit (Figure S5). The asymmetric unit contains one and a half $\mathrm{Cd}^{2+}$ ions, one SIPA ligand, one and a half ABPY ligands, one coordinated DMF molecule, and one lattice DMF molecule along with two methanol molecules. One of the $\mathrm{Cd}$ atoms, $\mathrm{Cd}(2)$, occupies a special position (1a) with a site multiplicity of 0.5 . Both the $\mathrm{Cd}$ atoms have a distorted octahedral geometry formed by four oxygen and two nitrogen atoms. $\mathrm{Cd}(1)$ is bonded with four oxygen atoms of SIPA carboxylates and two ABPY ligands, whereas $\mathrm{Cd}(2)$ is bonded with two sulfo groups of SIPA ligand, two ABPY ligands, and two DMF molecules. The $\mathrm{Cd}-\mathrm{O} / \mathrm{N}$ bond lengths are in the range 2.275(1)-2.385(3) $\AA$ (Table S3).

The carboxylate groups of the SIPA ligand have different bonding with the cadmium centers. Thus, one carboxylate forms a $\mu_{1}-\eta^{1}: \eta^{1}$-chelating coordination and the other forms a $\mu_{2}-\eta^{1}: \eta^{1}$-bridging coordination modes to form a $\left[\mathrm{Cd}_{2}\left(\mathrm{CO}_{2}\right)_{4}\right]$ unit (Figure 1a). This connectivity gives rise to a onedimensional (1D) double chain along the $a$ axis (Figure $1 \mathrm{~b}$ ). The 1D double chains are bonded with the $\mathrm{Cd}(2)$ atom via a $\mu_{1}-\eta^{1}: \eta^{0}$ monodentate coordination mode through the sulfonate group forming a two-dimensional (2D) layer (Figure $1 \mathrm{c}-\mathrm{d})$. The 2D layers are connected to each other through the $\mathrm{ABPY}$ ligands giving rise to the $3 \mathrm{D}$ structure (Figure 1e). This connectivity results in a 1D pore with a diameter of $\sim 5.0 \AA \times$ $\sim 8.0 \AA$ (atom-atom contact distance not including the van der Waals radii) along the $a$ axis (Figure S6). The extraframework DMF and methanol molecules are located inside the 1D channels in the structure (Figure S7). The solvent molecules are stabilized by a number of noncovalent interactions with the pore surface. The prominent $\mathrm{C}-\mathrm{H} \cdots \mathrm{O}$ interactions and their distances are shown (Figure $\mathrm{S} 8$ ).

Structure of $\left[\mathrm{Cd}_{3}\left(\mathrm{C}_{8} \mathrm{H}_{3} \mathrm{SO}_{7}\right)_{2}\left(\mathrm{C}_{12} \mathrm{H}_{10} \mathrm{~N}_{4}\right)_{3}\left(\mathrm{C}_{3} \mathrm{H}_{7} \mathrm{NO}\right)_{2}\right]-$ $\left(\mathrm{C}_{12} \mathrm{H}_{10} \mathrm{~N}_{4}\right) \cdot\left(\mathrm{C}_{3} \mathrm{H}_{7} \mathrm{NO}\right)_{2}$ (II). The structure of II is similar to that of I. Compound II has 60 non-hydrogen atoms, which contains one and a half $\mathrm{Cd}^{2+}$ ions, one SIPA ligand, one and a half coordinated BPDB ligands, and half noncoordinated BPDB ligand, one bonded DMF molecule along with a half nonbonded DMF molecule (Figure S9). One of the cadmium atoms, $\mathrm{Cd}(2)$, occupies a special position $(1 a)$ with site multiplicity of 0.5 . Both $\mathrm{Cd}(1)$ and $\mathrm{Cd}(2)$ have octahedral geometry with $\mathrm{Cd}(1)$ connected with four carboxylate oxygens and two nitrogens of BPDB ligands, and $\mathrm{Cd}(2)$ is bonded with two sulfo oxygens of SIPA, two DMF oxygens, and two nitrogens of BPDB ligand. The $\mathrm{Cd}-\mathrm{O} / \mathrm{N}$ bond length is in the range 2.271(6)-2.400(4) $\AA$ (Table S3).

The structure of II has connectivities that are similar to that observed in I. Thus, a 1D double chain formed by the connectivities between the $\mathrm{Cd}^{2+}$ centers and sulphonare oxygens are further bonded through the sulfonate oxygen involving $\mathrm{Cd}(2)$ forms a $2 \mathrm{D}$ layer. The $2 \mathrm{D}$ layers are further connected by the BPDB linkers to form the 3D structure (Figure 2). This connectivity gives rise to a $1 \mathrm{D}$ channel $(\sim 7.0$ $\AA \times \sim 9.0 \AA$ ) along the $a$ axis (Figure S10). In structure II, we observed that one unbounded BPDB molecule along with DMF molecules resides inside the channels (Figure S11), which nearly fills the channel.

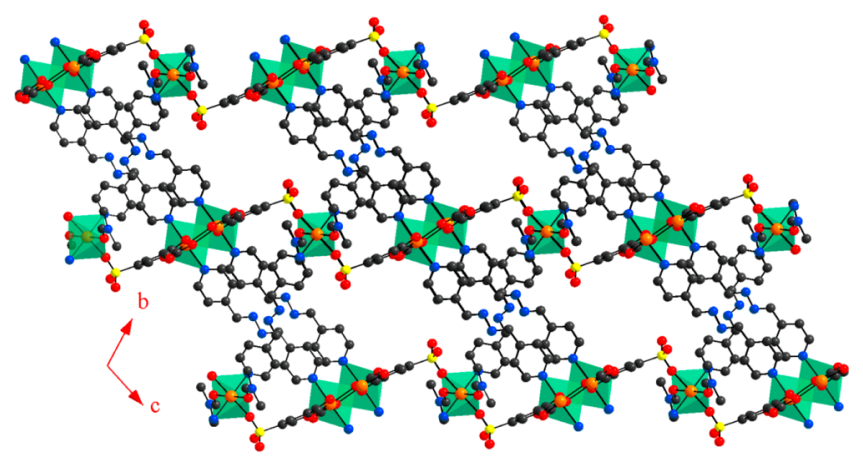

Figure 2. View of 3D structure of II (lattice solvent, ligands, and hydrogens are removed for clarity; $\mathrm{Cd}$ atoms are shown in green colored polyhedral). Benzaldehyde dimethyl acetal (BA), benzaldehyde (BD), benzyledene malononitrile (BM).

Thermal Stability and Gas Adsorption Studies. Thermogravimetric analysis (TGA) (Mettler-Toledo) of the compounds was carried out in the temperature range of 30$850^{\circ} \mathrm{C}$ (heating rate $=5^{\circ} \mathrm{C} / \mathrm{min}$ ) in oxygen atmosphere (flow rate $=50 \mathrm{~mL} / \mathrm{min}$ ) (Figure S12). Both the compounds exhibited similar behavior. For compound I, a continuous weight loss up to $175^{\circ} \mathrm{C}$, followed by a sharp weight loss in the temperature range of $315-500{ }^{\circ} \mathrm{C}$ was noted. The total observed weight loss was $79.2 \%$, which would correspond to the loss of all the organic moieties $(81.1 \%)$ present in the compound. A similar behavior was also noted for compound II with the total observed weight loss of $80.9 \%$ (calculated for the loss of organic moieties $82.8 \%$ ). The final calcined product in both cases was found to be CdO (ICSD - 24802) (Figure S13).

The thermal stability of the compounds was also examined by employing variable temperature in situ (up to $483 \mathrm{~K}$ ) powder X-ray diffraction (HTPXRD) studies (Figure S14) (Rigaku, SmartLab rotating anode diffractometer $\left(\mathrm{CuK}_{\alpha}\right.$ radiation) employing an alumina $\left(\mathrm{Al}_{2} \mathrm{O}_{3}\right)$ sample holder. The in situ PXRD studies suggest that both I and II appear to be stable up to $483 \mathrm{~K}$. The broad peak observed near $2 \theta=6^{\circ}$ was from the sample holder. The HTPXRD studies also confirm that the gradual weight loss observed in the TGA is mainly due to the loss of the solvent molecules from the framework, and the collapse of the framework starts only after $\sim 300{ }^{\circ} \mathrm{C}$. It may be noted that the overall crystallinity of the compounds was slightly reduced at higher temperatures (Figure S14). The calcined sample $(483 \mathrm{~K})$ was examined employing proton NMR as well as elemental analysis to verify the removal of the solvent molecules (DMF) from the framework (Figure S15 and Table S2). The studies indicate that at $483 \mathrm{~K}$, most of the DMF molecules have been removed.

Catalysis. The present compounds appear to possess more than one functional group. Thus, we have explored both the compounds, I and II, as a heterogeneous catalyst in a one-pot tandem deacetalization-Knoevenagel condensation reaction. The deacetalization reaction, generally, is acid-catalyzed and produces aldehydes or ketones. The base-catalyzed Knoevenagel condensation reaction can form nitriles. The catalytic conditions were optimized by carrying out the reaction by changing the temperature, solvent, and catalyst amount (Table S5). As mentioned in the Experimental Section, the optimal conditions are $T=353 \mathrm{~K}$, solvent $=\mathrm{DMF}$, and catalyst $=0.56$ $\mathrm{mol} \%(10 \mathrm{mg}$ for I and $11 \mathrm{mg}$ for II). In the present study, the deacetalization reaction produces benzaldehyde (BD) from 
benzaldehyde dimethyl acetal (BA) as a reactant, which is acidcatalyzed. The base-catalyzed Knoevenagel condensation reaction produces benzylidene malononitrile (BM) in the presence of the reactants $\mathrm{BD}$ and malononitrile $(\mathrm{MN})$.

Initially, we have carried out the two reactions separately to monitor which one is the rate determining step. The first step, the deacetalization reaction, was found to be slow with conversion of $\sim 15 \%$ after $5 \mathrm{~h}$ of reaction at $353 \mathrm{~K}$. The formation of aldehyde did not improve much even when the reaction was carried out for $12 \mathrm{~h}$. The Knoevenagel reaction, on the other hand, was found to be fast under the same reaction conditions. Typically the reaction was observed to be complete within $\sim 3.5 \mathrm{~h}$ for I and $\sim 3 \mathrm{~h}$ for II. The superior conversion in the Knoevenagel reaction inspired us to carry out a tandem DK reaction by keeping the amounts of the reactants and the other experimental conditions constant (Scheme 1).

Scheme 1. Scheme for the One-Pot Tandem

Deacetalization-Knoevenagel Reaction<smiles>COC(OC)c1ccccc1</smiles><smiles>CC(=O)c1ccccc1</smiles><smiles>N#CC(C#N)=Cc1cccc(O)c1</smiles>

The tandem reaction was found to be successful with yields of $\sim 84 \%$ (I) and $\sim 95 \%$ (II) after $5 \mathrm{~h}$ of reaction at $353 \mathrm{~K}$. The higher yields of the product in the tandem reaction are the result of the aldehyde formed by the Lewis acid catalyzed reaction being consumed immediately by the Lewis base catalysis. As observed in the separate experiments, the Lewis base catalyzed reaction was much faster, which helped convert the acetal immediately to the nitrile. This would facilitate the first reaction to proceed in the forward direction in a facile manner due to Le Chatelier's principle. The recyclability of the catalysts in this tandem reaction was tested up to three cycles, which does not indicate any major drop in the catalytic activity (Figure S16). The PXRD pattern of the catalysts also did not reveal any appreciable changes in the crystallinity after the third cycle of the catalytic studies (Figure S17). The success of the tandem catalysis prompted us to investigate the DK catalytic reactions employing other substituted $\mathrm{BA}$, and the results are listed in Table 2 (Figure S18). From the studies it appears that the yields of the para-substituted methoxy $\left(-\mathrm{OCH}_{3}\right)$ and bromo $(-\mathrm{Br})$ groups are comparable to the nonsubstituted $\mathrm{BA}$ under the same reaction conditions. On the other hand, the reaction does not proceed well when phenylacetaldehyde dimethyl acetal was employed. Similar behavior has been noted earlier. ${ }^{56}$ It is likely that the

Table 2. One-Pot Tandem Catalysis Yield with the Heterogeneous Catalysts Compounds I and II $^{a}$

\begin{tabular}{|c|c|c|c|}
\hline & II \\
\hline & Substrate & \multicolumn{2}{|c|}{ \% of Yield } \\
\hline
\end{tabular}

${ }^{a}$ Reaction conditions: Benzaldehyde dimethyl acetal $(1 \mathrm{mmol})$, malononitrile $(1 \mathrm{mmol})$, DMF $(2 \mathrm{~mL})$, and catalyst $(0.56 \mathrm{~mol} \%$; $10 \mathrm{mg}$ of compound I/11 mg of compound II). The yields were determined by employing silica gel column chromatography after $5 \mathrm{~h}$ of reaction. 
substitution at the $\alpha$ position does not provide the needed delocalization energy. We have also attempted to carry out the tandem reactions in a solvent-free condition at $353 \mathrm{~K}$. Solventfree reactions provide an opportunity to achieve a greener and more sustainable route of chemical transformations. ${ }^{57-60}$ Our studies indicate that the reactions do proceed to near completion albeit taking longer time $(\sim 15 \mathrm{~h})$. The catalysts also retain their crystallinity under the solvent-free catalytic reactions as well (Figure S19). An IR spectroscopic investigation on the catalysts after both solvent free as well as with DMF as the solvent catalytic reactions did not reveal any observable changes (Figure S20). The elemental analysis after the catalytic studies also did not reveal any changes (Table S2).

The catalytic studies indicate that II is more active compared to I. Structurally, compound I has more open pores compared to II. It is likely that the presence of free BPDB in II enhances the overall basicity in II and favors the aldehyde to nitrile reaction. In order to get a better insight into this reaction, we sought to carry out time dependent catalytic studies. For this reaction, we collected small quantities of the reaction mixture at regular intervals and analyzed employing NMR spectroscopy.

In a typical solvent-free tandem reaction, $25 \mathrm{mmol}$ of BA and $\mathrm{MN}$ along with $250 \mathrm{mg}$ of I and $275 \mathrm{mg}$ of II were reacted at $353 \mathrm{~K}$. Dimethyl terephthalate $(0.077 \mathrm{mmol})$ was used as an internal standard for the NMR study. A small aliquot (0.064 $\mathrm{mL}$ ) was removed from the reaction mixture using a syringe starting from $t=0$ (beginning of the reaction) followed by every $3 \mathrm{~h}$. The mixture was transferred to the NMR tube along with the internal standard and $\mathrm{CDCl}_{3}$ as the NMR solvent (Figures S21-22). The distributions of the products from the experiments are shown in Figure 3. The distribution of the reactants and the products employing I and II appears to be showing similar trends. Initially the conversion is slow, and it becomes maximum in between 9 and $12 \mathrm{~h}$ for $\mathbf{I}$ and it is in between 6 and $9 \mathrm{~h}$ for II and then the saturation occurs. In addition, the product formation appears to be faster when II was employed as the catalyst. It was found that after $15 \mathrm{~h}$ the amount of reactants was negligible in the case of II. A similar observation was also noted employing DMF as the solvent. It is clear that the catalytic activity of II is superior to that of I. We have also carried out a hot filtration test to prove the heterogeneity of the reaction.

The deacetalization-Knoevenagel catalytic reactions have been carried out by employing MOFs (Table 3). As can be seen, the present compounds are active and exhibit catalytic activity that is comparable to those reported earlier. ${ }^{42-45,66-69}$ It may be noted that in the present study no postsynthetic modifications or nanoparticle incorporation have been carried out, and the compounds were used as synthesized. In addition, the Cd-MOFs exhibit catalytic activity with minimal quantity of solvent, which would be desirable for environmental reasons and a green process.

Proton Conductivity. The TGA investigations along with in situ PXRD and IR studies suggest that the solvent molecules may be removed without collapse of the framework. We wanted to explore the water absorption capability of the preheated samples of the compounds I and II (BELSORB aqua). The water sorption isotherm studies indicate a gradual water uptake, which reaches a value of $157 \mathrm{~mL} / \mathrm{g}$ at $p / p_{0}=0.9$ and $104 \mathrm{~mL} / \mathrm{g}$ at $p / p_{0}=0.9$ for compounds I and II, respectively (Figure S23). The adsorbed water would

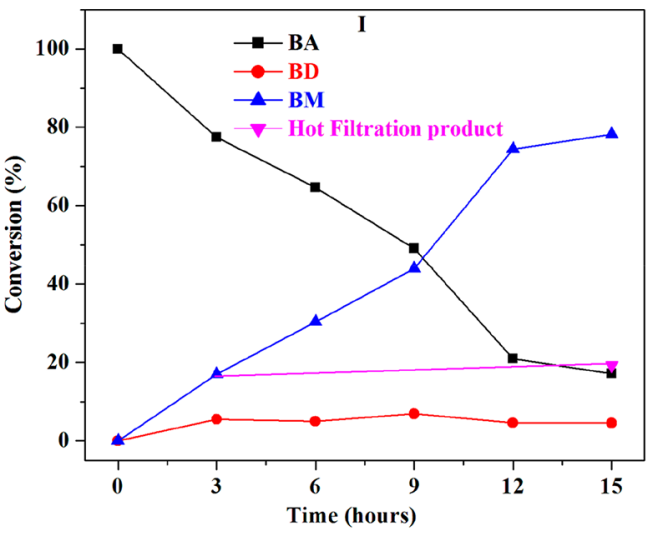

(a)

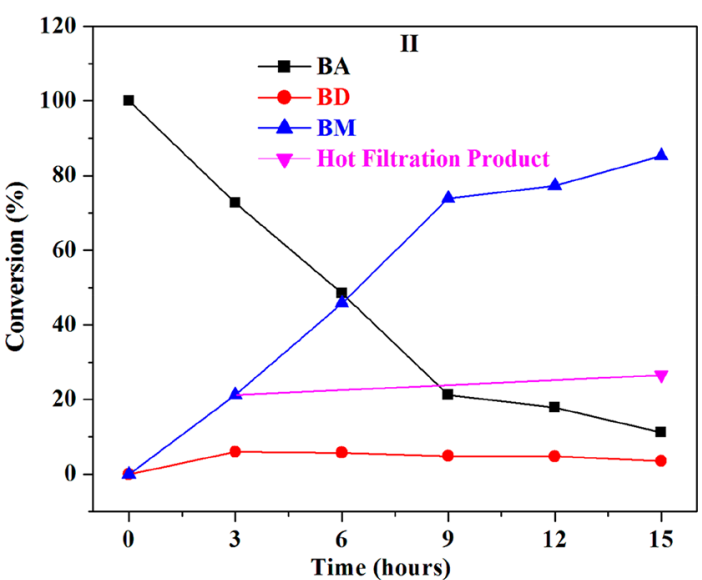

(b)

Figure 3. Kinetic study for the one-pot tandem deacetalizationKnoevenagel reaction with I (a) and II (b) as a heterogeneous catalysts (solvent-free condition).

correspond to $12.5 \mathrm{~mol}$ of $\mathrm{H}_{2} \mathrm{O} / \mathrm{mol}$ of $\mathbf{I}$ and $9.1 \mathrm{~mol}$ of $\mathrm{H}_{2} \mathrm{O} / \mathrm{mol}$ of II. Compound I exhibits a higher water uptake compared to II due to the presence of more open channels. The adsorption isotherm for both the compounds exhibits a hysteresis, which does not close at lower partial pressures. This suggests that the pores could be hydrophilic in nature and can absorb water irreversibly. The PXRD pattern of the water absorbed sample does not show any observable changes, which suggests that the compounds retain their structures (Figure S24).

The water adsorption studies indicated that the compound I uptakes a considerable amount of water. Structurally I contains pores that are decorated by sulfonate moieties, which opens up the possibility of accommodating the lattice water molecules either as clusters or chains along the 1D channel. There have been reports of proton mobility in compounds having sulfonate functionality along with the solvent molecules. This prompted us to investigate the possible proton conductivity in I. A pellet of compound I was prepared and kept at $98 \%$ humidity chamber at room temperature for $24 \mathrm{~h}$. The measurement was carried out in the frequency range of $0.1-$ $10^{6} \mathrm{~Hz}$ with the signal amplitude of $0.12 \mathrm{~V}$ (Alpha, Novocontrol). A proton conductivity value of $0.86 \times 10^{-4}$ $\Omega^{-1} \mathrm{~cm}^{-1}$ was observed from the Nyquist plots for compound I at $30{ }^{\circ} \mathrm{C}$ (Figure 4). The proton conductivity behavior of I found to be temperature dependent as the value was found to 
Table 3. Table Summarizing the Various MOF Catalysts Employed in the Tandem Deacetalization-Knoevenagel Condensation Reaction $^{a}$

\begin{tabular}{|c|c|c|c|c|c|c|}
\hline name of catalyst & catalyst amount & solvent & temp $\left({ }^{\circ} \mathrm{C}\right)$ & reaction time & yield $(\%)$ & ref \\
\hline $\mathrm{Cu}-\mathrm{PCN}-126$ & $0.5 \mathrm{~mol} \mathrm{\%}$ & DMSO & 50 & $12 \mathrm{~h}$ & 99 & 42 \\
\hline Cr-MIL-101-AB-x & $4 \mathrm{~mol} \mathrm{\%}$ & DMF & 90 & $2 \mathrm{~h}$ & $>91$ & 43 \\
\hline $\mathrm{Yb}-\mathrm{BDC}-\mathrm{NH}_{2}$ & $2 \mathrm{~mol} \%$ & DMSO & 50 & $24 \mathrm{~h}$ & 97 & 44 \\
\hline MIL-101(Al)- $\mathrm{NH}_{2}$ & $100 \mathrm{mg}$ & 1,4-dioxane & 90 & $3 \mathrm{~h}$ & 94 & 45 \\
\hline $\mathrm{Fe}_{3} \mathrm{O}_{4} @ \mathrm{Cu}$-HKUST-1 & $50 \mathrm{mg}$ & 1,4-dioxane & 90 & $5 \mathrm{~h}$ & 99 & 66 \\
\hline Cu-HNUST-8 & $0.5 \mathrm{~mol} \%$ & DMSO & 50 & $48 \mathrm{~h}$ & 99 & 67 \\
\hline Cu-HNUST-6 & $0.5 \mathrm{~mol} \%$ & DMSO & 50 & $48 \mathrm{~h}$ & 99 & 68 \\
\hline PBSA/Cr-MIL-101 + PMAP/Cr-MIL-101 & $5 \mathrm{~mol} \mathrm{\%}$ & $\mathrm{DMSO} / \mathrm{H}_{2} \mathrm{O}$ & 70 & $12 \mathrm{~h}$ & 89 & 69 \\
\hline Compound I & $0.56 \mathrm{~mol} \%$ & $\mathrm{DMF}$ & 90 & $5 \mathrm{~h}$ & 84 & this work \\
\hline Compound II & $0.56 \mathrm{~mol} \mathrm{\%}$ & $\mathrm{DMF}$ & 90 & $5 \mathrm{~h}$ & 95 & this work \\
\hline
\end{tabular}

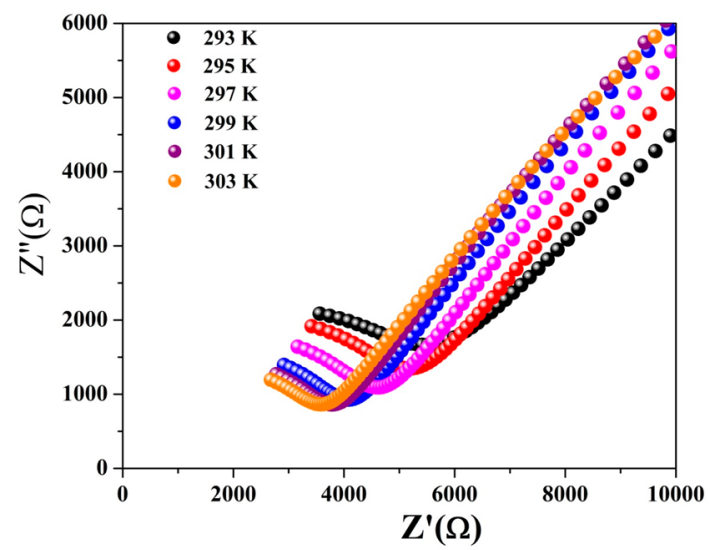

Figure 4. Proton conductivity study for I: Nyquist plots at different temperatures are shown (relative humidity of $98 \%$ was maintained).

increase with the increase of temperature (Figure 4). The observed proton conductivity value at RT was found to be comparable with those reported elsewhere. The activation energy was calculated from the Arrhenius plot, which gave a value of $0.3 \mathrm{eV}$, suggesting a possible Grotthus mechanism in this compound (Figure S25). ${ }^{61-65}$

\section{CONCLUSION}

Two new 3D MOFs $\left[\mathrm{Cd}_{3}\left(\mathrm{C}_{8} \mathrm{H}_{3} \mathrm{SO}_{7}\right)_{2}\left(\mathrm{C}_{10} \mathrm{H}_{8} \mathrm{~N}_{4}\right)_{3}\right.$ $\left.\left(\mathrm{C}_{3} \mathrm{H}_{7} \mathrm{NO}\right)_{2}\right]\left(\mathrm{C}_{3} \mathrm{H}_{7} \mathrm{NO}\right)_{2} \cdot\left(\mathrm{CH}_{3} \mathrm{OH}\right)_{4}$ (I) and $\left[\mathrm{Cd}_{3}\left(\mathrm{C}_{8} \mathrm{H}_{3} \mathrm{SO}_{7}\right)_{2}\left(\mathrm{C}_{12} \mathrm{H}_{10} \mathrm{~N}_{4}\right)_{3}\left(\mathrm{C}_{3} \mathrm{H}_{7} \mathrm{NO}\right)_{2}\right]\left(\mathrm{C}_{12} \mathrm{H}_{10} \mathrm{~N}_{4}\right)$. $\left(\mathrm{C}_{3} \mathrm{H}_{7} \mathrm{NO}\right)_{2}$ (II) have been prepared and their structures were determined. The compounds have 3D structures with $\mathrm{I}$ having 1D open channels. The compounds exhibit both Lewis acidic (from Cd center) as well as Lewis basic (from the sulfo oxygens and azine/free pyridyl group) functionality. The dual functionality was exploited for the one-pot tandem deacetalization-Knoevenagel reaction both under the solvent as well as solvent-free conditions. Our studies reveal that compound II is more active for the tandem catalysis compared to compound I, possibly due to the presence of azine functionality and uncoordinated BPDB linkers. Proton conductivity studies on I indicate moderate proton conductivity behavior at room temperature.

\section{ASSOCIATED CONTENT}

S Supporting Information

The Supporting Information is available free of charge on the ACS Publications website at DOI: 10.1021/acs.cgd.8b01327.

Synthesis composition table, elemental analysis results, selected bond distances and angles of the compounds, PXRD patterns, IR spectra, PL spectra, space filled views, views of lattice solvent molecules, TGA plots, ${ }^{1} \mathrm{H}$ NMR results, optimization of reaction condition for the deacetalization-Knoevenagel catalytic reaction, recyclability of the catalysts, adsorption-desorption isotherms, activation energy (PDF)

\section{Accession Codes}

CCDC 1838396-1838397 contain the supplementary crystallographic data for this paper. These data can be obtained free of charge via www.ccdc.cam.ac.uk/data_request/cif, or by emailing data_request@ccdc.cam.ac.uk, or by contacting The Cambridge Crystallographic Data Centre, 12 Union Road, Cambridge CB2 1EZ, UK; fax: +44 1223336033.

\section{AUTHOR INFORMATION}

\section{Corresponding Author}

*E-mail: snatarajan@iisc.ac.in.

ORCID

Srinivasan Natarajan: 0000-0002-4942-0968

Notes

The authors declare no competing financial interest.

\section{ACKNOWLEDGMENTS}

S.N. thanks Science and Engineering Research Board (SERB), Government of India, for the award of a J. C. Bose National Fellowship. S.N. also thanks the Council of Scientific and Industrial Research (CSIR), Government of India for the award of a research grant. The authors thank Prof. R. Ranjan and Mr. A. Dey (Materials Engineering, IISc) and Prof. A. J. Bhattacharyya for their help with the in situ HTPXRD and proton conductivity studies.

\section{REFERENCES}

(1) Zhou, H. C. J.; Kitagawa, S. Metal-Organic Frameworks (MOFs). Chem. Soc. Rev. 2014, 43, 5415-5418.

(2) Zhou, H. C.; Long, J. R.; Yaghi, O. M. Introduction to Metal Organic Frameworks. Chem. Rev. 2012, 112, 673-1268.

(3) Special Issue on Metal Organic Frameworks. Eur. J. Inorg. Chem. 2010, 24, 3683-3874. 
(4) Special Issue on Metal Organic Frameworks. Chem. Soc. Rev. 2009, 38, 1201-1508.

(5) Kreno, L. E.; Leong, K.; Farha, O. K.; Allendorf, M.; Van Duyne, R. P.; Hupp, J. T. Metal-Organic Framework Materials as Chemical Sensors. Chem. Rev. 2012, 112, 1105-1125.

(6) Sumida, K.; Rogow, D. L.; Mason, J. A.; McDonald, T. M.; Bloch, E. D.; Herm, Z. R.; Bae, T.-H.; Long, J. R. Carbon Dioxide Capture in Metal-Organic Frameworks. Chem. Rev. 2012, 112, 724781.

(7) Zeng, L.; Guo, X.; He, C.; Duan, C. Metal-Organic Frameworks: Versatile Materials for Heterogeneous Photocatalysis. ACS Catal. 2016, 6, 7935-7947.

(8) Tan, L.; Tan, B. Correction: Hypercrosslinked porous polymer materials: design, synthesis, and applications. Chem. Soc. Rev. 2017, 46, 3481-3481a.

(9) Barea, E.; Montoro, C.; Navarro, J. A. R. Toxic gas removalmetal-organic frameworks for the capture and degradation of toxic gases and vapours. Chem. Soc. Rev. 2014, 43, 5419-5430.

(10) Canivet, J.; Fateeva, A.; Guo, Y.; Coasne, B.; Farrusseng, D. Water adsorption in MOFs: fundamentals and applications. Chem. Soc. Rev. 2014, 43, 5594-5617.

(11) Tsivion, E.; Head-Gordon, M. Methane Storage: Molecular Mechanisms Underlying RoomTemperature Adsorption in $\mathrm{Zn}_{4} \mathrm{O}$ (BDC) ${ }_{3}$ (MOF-5). J. Phys. Chem. C 2017, 121, 12091-12100.

(12) Zhang, Z.; Yao, Z. Z.; Xiang, S.; Chen, B. Perspective of microporous metal-organic frameworks for $\mathrm{CO}_{2}$ capture and separation. Energy Environ. Sci. 2014, 7, 2868-2899.

(13) Schröder, M. Functional Metal-Organic Frameworks: Gas Storage, Separation and Catalysis; Springer, 2010.

(14) Hartlieb, K. J.; Holcroft, J. M.; Moghadam, P. Z.; Vermeulen, N. A.; Algaradah, M. M.; Nassar, M. S.; Botros, Y. Y.; Snurr, R. Q.; Stoddart, J. F. CD-MOF: A Versatile Separation Medium. J. Am. Chem. Soc. 2016, 138, 2292-2301.

(15) DeCoste, J. B.; Peterson, G. W. Metal-Organic Frameworks for Air Purification of Toxic Chemicals. Chem. Rev. 2014, 114, 56955727.

(16) Fu, J.; Das, S.; Xing, G.; Ben, T.; Valtchev, V.; Qiu, S. Fabrication of COF-MOF Composite Membranes and Their Highly Selective Separation of H2/CO2. J. Am. Chem. Soc. 2016, 138, 76737680.

(17) Xamena, F. X. L. Ú.; Gascon, J. Metal Organic Frameworks as Heterogeneous Catalysts; Royal Society of Chemistry, 2013.

(18) Yoon, M.; Srirambalaji, R.; Kim, K. Homochiral MetalOrganic Frameworks for Asymmetric Heterogeneous Catalysis. Chem. Rev. 2012, 112, 1196-1231.

(19) Shen, K.; Chen, X.; Chen, J.; Li, Y. Development of MOFDerived Carbon-Based Nanomaterials for Efficient Catalysis. ACS Catal. 2016, 6, 5887-5903.

(20) Yoshimaru, S.; Sadakiyo, M.; Staykov, A.; Kato, K.; Yamauchi, M. Modulation of the catalytic activity of Pt nanoparticles through charge-transfer interactions with metal-organic frameworks. Chem. Commun. 2017, 53, 6720-6723.

(21) Platero-Prats, A. E.; Li, Z.; Gallington, L. C.; Peters, A. W.; Hupp, J. T.; Farha, O. K.; Chapman, K. W. Addressing the characterisation challenge to understand catalysis in MOFs: the case of nanoscale $\mathrm{Cu}$ supported in NU-1000. Faraday Discuss. 2017, 201, 337-350.

(22) Dutta, G.; Jana, A. K.; Natarajan, S. Assembling Porphyrins into Extended Network Structures by Employing Aromatic Dicarboxylates: Synthesis, Metal Exchange, and Heterogeneous Catalytic Studies. Chem. - Eur. J. 2017, 23, 8932-8940.

(23) Gao, X.; Zhai, M.; Guan, W.; Liu, J.; Liu, Z.; Damirin, A. Controllable Synthesis of a Smart Multifunctional Nanoscale MetalOrganic Framework for Magnetic Resonance/Optical Imaging and Targeted Drug Delivery. ACS Appl. Mater. Interfaces 2017, 9, 34553462.

(24) Teplensky, M. H.; Fantham, M.; Li, P.; Wang, T. C.; Mehta, J. P.; Young, L. J.; Moghadam, P. Z.; Hupp, J. T.; Farha, O. K.; Kaminski, C. F.; Fairen-Jimenez, D. Temperature Treatment of
Highly Porous Zirconium-Containing Metal-Organic Frameworks Extends Drug Delivery Release. J. Am. Chem. Soc. 2017, 139, 75227532.

(25) Levine, D. J.; Runcevski, T.; Kapelewski, M. T.; Keitz, B. K.; Oktawiec, J.; Reed, D. A.; Mason, J. A.; Jiang, H. Z. H.; Colwell, K. A.; Legendre, C. M.; FitzGerald, S. A.; Long, J. R. Olsalazine-Based Metal-Organic Frameworks as Biocompatible Platforms for H2 Adsorption and Drug Delivery. J. Am. Chem. Soc. 2016, 138, 1014310150 .

(26) Heine, J.; Müller-Buschbaum, K. Engineering metal-based luminescence in coordination polymers and metal-organic frameworks. Chem. Soc. Rev. 2013, 42, 9232-9242.

(27) Xu, H.; Cao, C. S.; Kang, X. M.; Zhao, B. Lanthanide-based metal-organic frameworks as luminescent probes. Dalton Trans 2016, 45, 18003-18017.

(28) Chughtai, A. H.; Ahmad, N.; Younus, H. A.; Laypkov, A.; Verpoort, F. Metal-organic frameworks: versatile heterogeneous catalysts for efficient catalytic organic transformations. Chem. Soc. Rev. 2015, 44, 6804-6849.

(29) Felpin, F.-X.; Fouquet, E. Heterogeneous Multifunctional Catalysts for Tandem Processes: An Approach toward Sustainability. ChemSusChem 2008, 1, 718-724.

(30) Hayashi, Y. Pot economy and one-pot synthesis. Chem. Sci. 2016, 7, 866-880.

(31) Vaxelaire, C.; Winter, P.; Christmann, M. One-Pot Reactions Accelerate the Synthesis of Active Pharmaceutical Ingredients. Angew. Chem., Int. Ed. 2011, 50, 3605-3607.

(32) Huang, Y.-B.; Liang, J.; Wang, X.-S.; Cao, R. Multifunctional metal-organic framework catalysts: synergistic catalysis and tandem reactions. Chem. Soc. Rev. 2017, 46, 126-157.

(33) He, Y.; Li, B.; O’Keeffe, M.; Chen, B. Multifunctional metalorganic frameworks constructed from meta-benzenedicarboxylate units. Chem. Soc. Rev. 2014, 43, 5618-5656.

(34) Jain, S.; Ramachary, D. B. Sequential one-pot combination of multi-component and multi-catalysis cascade reactions: an emerging technology in organic synthesis. Org. Biomol. Chem. 2011, 9, 12771300.

(35) Climent, M. J.; Corma, A.; Iborra, S.; Sabater, M. J. Heterogeneous Catalysis for Tendem Reactions. ACS Catal. 2014, 4, 870-891.

(36) Verma, A.; Tomar, K.; Bharadwaj, P. K. Chiral Cadmium (II) Metal-Organic Framework from an Achiral Ligand by Spontaneous Resolution: An Efficient Heterogeneous Catalyst for the Strecker Reaction of Ketones. Inorg. Chem. 2017, 56, 13629-13633.

(37) Jiang, W.; Yang, J.; Liu, Y.-Y.; Song, S.-Y.; Ma, J.-F. A Stable Porphyrin-Based Porous mog Metal-Organic Framework as an Efficient Solvent-Free Catalyst for $\mathrm{C}-\mathrm{C}$ Bond Formation. Inorg. Chem. 2017, 56, 3036-3043.

(38) Farrusseng, D.; Aguado, S.; Pinel, C. Metal-Organic Frameworks: Opportunities for Catalysis. Angew. Chem., Int. Ed. 2009, 48, $7502-7513$.

(39) Roshan, K. R.; Palissery, R. A.; Kathalikkattil, A. C.; Babu, R.; Mathai, G.; Lee, H.-S.; Park, D.-W. A computational study of the mechanistic insights into base catalysed synthesis of cyclic carbonates from $\mathrm{CO}_{2}$ : bicarbonate anion as an active species. Catal. Sci. Technol. 2016, 6, 3997-4004.

(40) Masoomi, M. Y.; Beheshti, S.; Morsali, A. Mechanosynthesis of new azine-functionalized $\mathrm{Zn}$ (II) metal-organic frameworks for improved catalytic performance. J. Mater. Chem. A 2014, 2, 1686316866.

(41) Masoomi, M. Y.; Stylianou, K. C.; Morsali, A.; Retailleau, P.; Maspoch, D. Selective CO2 Capture in Metal-Organic Frameworks with AzineFunctionalized Pores Generated by Mechanosynthesis. Cryst. Growth Des. 2014, 14, 2092-209.

(42) Park, J.; Li, J.-R.; Chen, Y.-P.; Yu, J.; Yakovenko, A. A.; Wang, Z. U.; Sun, L.-B.; Balbuena, P. B.; Zhou, H.-C. A versatile metalorganic framework for carbon dioxide capture and cooperative catalysis. Chem. Commun. 2012, 48, 9995-9997. 
(43) Liu, H.; Xi, F.-G.; Sun, W.; Yang, N.-N.; Gao, E.-Q. Amino- and Sulfo-Bifunctionalized Metal-Organic Frameworks: OnePot Tandem Catalysis and the Catalytic Sites. Inorg. Chem. 2016, 55, 5753-5755.

(44) Zhang, Y.; Wang, Y.; Liu, L.; Wei, N.; Gao, M.-L.; Zhao, D.; Han, Z.-B. Robust Bifunctional Lanthanide Cluster Based MetalOrganic Frameworks (MOFs) for Tandem Deacetalization-Knoevenagel Reaction. Inorg. Chem. 2018, 57, 2193-2198.

(45) Toyao, T.; Fujiwaki, M.; Horiuchi, Y.; Matsuoka, M. Application of an amino-functionalised metal-organic framework: an approach to a one-pot acid-base reaction. RSC $A d v$. 2013, 3, 21582-21587.

(46) Kennedy, A. R.; Brown, K. G.; Graham, D.; Kirkhouse, J. B.; Kittner, M.; Major, C.; McHugh, C. J.; Murdoch, P.; Smith, W. E. Chromophore containing bipyridyl ligands. Part 1: supramolecular solid-state structure of Ag(I) complexes. New J. Chem. 2005, 29, 826832.

(47) Reimer, N.; Bueken, B.; Leubner, S.; Seidler, C.; Wark, M.; De Vos, D.; Stock, N. Three Series of Sulfo-Functionalized Mixed-Linker CAU-10 Analogues: Sorption Properties, Proton Conductivity, and Catalytic Activity. Chem. - Eur. J. 2015, 21, 12517-12524.

(48) Krishnakumar, B.; Selvam, K.; Swaminathan, M. Solar Catalytic Degradation of Naphthol Blue Black. Synth. Commun. 2011, 41, 1929-1937.

(49) Mistry, S.; Hota, R.; Natarajan, S. Selective Separation of Aliphatic Nitriles by Employing a Two-Dimensional Interdigitated Coordination Polymer. Chem. - Asian J. 2017, 12, 1807-1815.

(50) Brozek, C. K.; Michaelis, V. K.; Ong, T.-C.; Bellarosa, L.; Lopez, N.; Griffin, R. G.; Dinca, M. Dynamic DMF Binding in MOF5 Enables the Formation of Metastable Cobalt-Substituted MOF-5 Analogues. ACS Cent. Sci. 2015, 1, 252-260.

(51) Bhattacharya, S.; Sanyal, U.; Natarajan, S. Liquid-Liquid Interphase (Biphasic) as the Reaction Medium in the Assembly of a Hierarchy of Structures of 4,40 -Azodibenzoic Acid with Zinc and Cadmium. Cryst. Growth Des. 2011, 11, 735-747.

(52) Zhang, S.; Ma, J.; Zhang, X.; Duan, E.; Cheng, P. Assembly of Metal-Organic Frameworks Based on 3,3',5,5'- Azobenzenetetracarboxylic Acid: Photoluminescences, Magnetic Properties, and Gas Separations. Inorg. Chem. 2015, 54, 586-595.

(53) CrysAlis Pro Red, version 1.171.33.34d; Oxford Diffraction Ltd.: Abingdon, Oxfordshire, England, 2009.

(54) Sheldrick, G. M. SHELXS-97, Program for Crystal Structure Solution and Refinement; University of Göttingen: Göttingen, Germany, 1997.

(55) Farrugia, L. J. J. Appl. Crystallogr. 1999, 32, 837.

(56) Herbst, A.; Khutia, A.; Janiak, C. Brønsted Instead of Lewis Acidity in Functionalized MIL-101Cr MOFs for Efficient Heterogeneous (nano-MOF) Catalysis in the Condensation Reaction of Aldehydes with Alcohols. Inorg. Chem. 2014, 53, 7319-7333.

(57) Dhakshinamoorthy, A.; Asiri, A. M.; Alvaro, M.; Garcia, H. Metal organic frameworks as catalysts in solvent-free or ionic liquid assisted conditions. Green Chem. 2018, 20, 86-107.

(58) Liu, J.; Chen, L.; Cui, H.; Zhang, J.; Zhang, L.; Su, C.-Y. Applications of metal-organic frameworks in heterogeneous supramolecular catalysis. Chem. Soc. Rev. 2014, 43, 6011-6061.

(59) Gascon, J.; Corma, A.; Kapteijn, F.; Xamena, F. X. L. Metal Organic Framework Catalysis: Quo vadis? ACS Catal. 2014, 4, 361378.

(60) D’Vries, R. F.; Iglesias, M.; Snejko, N.; Gutiérrez-Puebla, E.; Monge, M. A. Lanthanide Metal-Organic Frameworks: Searching for Efficient Solvent-Free Catalysts. Inorg. Chem. 2012, 51, 1134911355

(61) Yoon, M.; Suh, K.; Natarajan, S.; Kim, K. Proton Conduction in Metal-Organic Frameworks and Related Modularly Built Porous Solids. Angew. Chem., Int. Ed. 2013, 52, 2688-2700.

(62) Ramaswamy, P.; Matsuda, R.; Kosaka, W.; Akiyama, G.; Jeon, H. J.; Kitagawa, S. Highly proton conductive nanoporous coordination polymers with sulfonic acid groups on the pore surface. Chem. Commun. 2014, 50, 1144-1146.
(63) Ramaswamy, P.; Wong, N. E.; Shimizu, G. K. H. MOFs as proton conductors-challenges and opportunities. Chem. Soc. Rev. 2014, 43, 5913-5932.

(64) Bhattacharya, S.; Bhattacharyya, A. J.; Natarajan, S. High Proton Mobility, Solvent Induced Single Crystal to Single Crystal Structural Transformation, and Related Studies on a Family of Compounds Formed from Mn3 Oxo-Clusters. Inorg. Chem. 2015, 54, 1254-1271.

(65) Bhattacharya, S.; Gnanavel, M.; Bhattacharyya, A. J.; Natarajan, S. Organization of Mn-Clusters in pcu and bcu Networks: Synthesis, Structure, and Properties. Cryst. Growth Des. 2014, 14, 310-325.

(66) Toyao, T.; Styles, M. J.; Yago, T.; Sadiq, M. M.; Ricco, R.; Suzuki, K.; Horiuchi, Y.; Takahashi, M.; Matsuoka, M.; Falcaro, P. $\mathrm{Fe}_{3} \mathrm{O}_{4} @$ HKUST-1 and $\mathrm{Pd} / \mathrm{Fe}_{3} \mathrm{O}_{4} @$ HKUST-1 as magnetically recyclable catalysts prepared via conversion from a $\mathrm{Cu}$-based ceramic. CrystEngComm 2017, 19, 4201-4210.

(67) Zheng, B.; Luo, X.; Wang, Z.; Zhang, S.; Yun, R.; Huang, L.; Zeng, W.; Liu, W. An unprecedented water stable acylamidefunctionalized metal-organic framework for highly efficient $\mathrm{CH}_{4} / \mathrm{CO}_{2}$ gas storage/separation and acid-base cooperative catalytic activity. Inorg. Chem. Front. 2018, 5, 2355-2363.

(68) Wang, Z.; Luo, X.; Zheng, B.; Huang, L.; Hang, C.; Jiao, Y.; Cao, X.; Zeng, W.; Yun, R. Highly Selective Carbon Dioxide Capture and Cooperative Catalysis of a Water-Stable Acylamide-Functionalized Metal-Organic Framework. Eur. J. Inorg. Chem. 2018, 2018, 1309-1314.

(69) Zhao, J.-H.; Yang, Y.; Che, J.-X.; Zuo, J.; Li, X.-H.; Hu, Y.-Z.; Dong, X.-W.; Gao, L.; Liu, X.-Y. Compartmentalization of Incompatible Polymers within Metal-Organic Frameworks towards Homogenization of Heterogeneous Hybrid Catalysts for Tandem Reactions. Chem. - Eur. J. 2018, 24, 9903-9909. 